\title{
CARACTERIZAÇÃO DA PRODUÇÃO CIENTÍFICA NA ÁREA DE INOVAÇÃo PEDAGÓGICA DO CURSO DE DOUTORADO DA UNIVERSIDADE DA MADEIRA
}

\author{
CARACTERIZACIÓN DE LA PRODUCCIÓN CIENTÍFICA EN EL ÁREA DE \\ INNOVACIÓN PEDAGÓGICA DEL CURSO DE DOCTORADO EN LA UNIVERSIDAD \\ DE MADEIRA
}

CHARACTERIZATION OF SCIENTIFIC PRODUCTION IN THE PEDAGOGICAL INNOVATION AREA OF THE PhD COURSE AT THE UNIVERSITY OF MADEIRA

\author{
Paulo BRAZÃO ${ }^{1}$ \\ Alfrancio Ferreira DIAS ${ }^{2}$ \\ Alice MENDONÇA ${ }^{3}$ \\ Lívia de Rezende CARDOSO ${ }^{4}$
}

RESUMO: Desde 2003, a existência de uma linha de pesquisa em Inovação Pedagógica no Centro de Investigação em Educação da Universidade da Madeira, possibilitou a ampliação da produção científica nesta área. Após esse tempo, urge sistematizar os aspetos identitários, os elementos epistemológicos e de boas práticas reconhecidas como inovadoras para o campo da Pedagogia e da Educação. Neste artigo apresentamos a parte inicial do projeto Inovação Pedagógica: Identidade, Teoria e Práticas (IPITP) onde caracterizamos a produção científica realizada na área de Inovação Pedagógica do curso de doutoramento da Universidade da Madeira (PT). Concluímos que os pesquisadores são maioritariamente femininos e de nacionalidade brasileira. Os temas mais investigados são os que possuem maior relação com o espaço escolar e tornam evidente a presença de invariantes culturais que dificultam a inovação pedagógica. $\mathrm{O}$ conhecimento oriundo destas pesquisas mostra a perfusão entre a teoria e a prática bem conjugada com o método de pesquisa descritiva utilizado.

PALAVRAS-CHAVE: Inovação pedagógica. Produção científica. IPITP. Educação.

RESUMEN: Desde 2003, la existencia de una línea de investigación en Innovación Pedagógica en el Centro de Investigación en Educación de la Universidad de Madeira ha permitido ampliar la producción científica en esta área. Después de ese tiempo, es urgente sistematizar los aspectos de identidad, los elementos epistemológicos y las buenas prácticas reconocidas como innovadoras para el campo de la pedagogía y la educación. Este artículo presenta el proyecto de Innovación pedagógica: identidad, teoría y praácticas (IPITP) y

\footnotetext{
${ }^{1}$ Universidade da Madeira (Uma), Funchal - Portugal. Professor Auxiliar e Pesquisador Centro de Investigação em Educação CIE-UMa. ORCID: http://orcid.org/0000-0003-3575-4366. E-mail: jbrazao@staff.uma.pt

${ }^{2}$ Universidade Federal de Sergipe (UFS), São Cristóvão - SE - Brasil. Professor do Programa de Pós-graduação em Educação. ORCID: https://orcid.org/0000-0002-5562-0085. E-mail: diasalfrancio@gmail.com

3 Universidade da Madeira (Uma), Funchal - Portugal. Professora Auxiliar e Pesquisadora Centro de Investigação em Educação CIE-UMa. ORCID: http://orcid.org/0000-0001-9726-9222. E-mail: alice.mendonca@staff.uma.pt

${ }^{4}$ Universidade Federal de Sergipe (UFS), São Cristóvão - SE - Brasil. Professora do Programa de Pósgraduação em Educação. ORCID: https://orcid.org/0000-0003-4091-9110. E-mail: livinha.bio@gmail.com
} 
caracteriza la producción científica en el área de Innovación pedagógica del curso de doctorado en la Universidad de Madeira (PT). Llegamos a la conclusión de que los investigadores son en su mayoría mujeres y de nacionalidad brasileña. Los temas más investigados son aquellos que tienen una mayor relación con el espacio escolar y evidencian la presencia de invariantes culturales que obstaculizan la innovación pedagógica. El conocimiento derivado de estas investigaciones muestra la perfusión entre teoría y práctica bien combinada con el método de investigación descriptivo utilizado.

PALABRAS CLAVE: Innovación pedagógica. Producción científica IPITP. Educación.

ABSTRACT: Since 2003, the existence of a line of research in Pedagogical Innovation at the Education Research Center of the University of Madeira, has made it possible to expand scientific production in this area. After that time, there is an urgent need to systematize the identity aspects, the epistemological elements and good practices recognized as innovative for the field of pedagogy and Education. This article presents the Pedagogical Innovation project: Identity, Theory and Practices (IPITP) and characterizes the scientific production in the Pedagogical Innovation area of the PhD course at the University of Madeira (PT). We conclude that the researchers are mostly female and of Brazilian nationality. The most investigated themes are those that have a greater relationship with the school space and make evident the presence of cultural invariants that hinder pedagogical innovation. The knowledge derived from these researches shows the perfusion between theory and practice well combined with the descriptive research method used.

KEYWORDS: Pedagogical innovation. Scientific production. IPITP. Education.

\section{Desafiar a educação através da inovação pedagógica}

A linha de pesquisa em Inovação Pedagógica no Centro de Investigação em Educação da Universidade da Madeira (CIE-UMa) surgiu em 2003 com um curso de mestrado em Ciências da Educação, ramo de Inovação Pedagógica. Em 2006, a UMa abriu o primeiro curso de doutoramento em Educação, na especialidade de Inovação Pedagógica. Os dois cursos mantiveram funcionamento ininterrupto até 2016 (FINO; SOUSA, 2016). Após processo avaliativo pela Comissão de Avaliação Externa da Agência de Avaliação do Ensino Superior português (A3ES), a Inovação Pedagógica renovou o seu propósito já num novo curso de $3^{\circ}$ ciclo do Ensino Superior - o doutoramento em Currículo e Inovação Pedagógica, atualmente em funcionamento. Por seu turno, o curso de mestrado em Inovação Pedagógica, acreditado pela mesma agência de avaliação, continua a funcionar respondendo às solicitações dos estudantes de $2^{\circ}$ ciclo do Ensino Superior.

O propósito do questionamento sobre os modos de agir pedagógicos aliado aos contextos específicos possibilitou um novo percurso na educação, um novo traçar de objetivos valorizando a criação e o fazer autónomo dos estudantes. É disso que trata a inovação 
pedagógica numa perspectiva de ruptura com o modelo tradicional e institucionalizado de ensino-aprendizagem que já não responde às solicitações culturais envolventes e que impõe a urgência de uma quebra de paradigma. Tal como Fino (2011) preconiza, a inovação pedagógica deve ser pautada por uma descontinuidade nas práticas pedagógicas tradicionais. Isso leva a que se desenvolva uma atualização dos modos de agir pedagógicos dos contextos ao nível micro incutindo-lhes um olhar crítico sobre a organização e o funcionamento dos sistemas educativos. Abordar a inovação pedagógica significa tratar de processos de aprendizagem e práticas pedagógicas de forma a devolver a autonomia aos estudantes para que realizem uma aprendizagem engajada.

Do ponto de vista curricular ${ }^{5}$, os dois cursos referenciados (mestrado e doutoramento) desta linha de pesquisa propõem-se analisar as revoluções, os paradigmas e a inovação pedagógica, partindo de um breve relato histórico das instituições educativas desde o modelo fabril, os princípios norteadores das revoluções culturais, abordando as quebras de paradigmas como modelos das dinâmicas descontínuas, até culminar no conceito de inovação pedagógica, com a reflexão sobre a autonomia da pessoa. (ALMADA; SOUSA, 2017; SOUSA; FINO, 2005).

Em ambos os cursos, a pesquisa empírica conduz os pesquisadores ao desenvolvimento de um olhar crítico dos contextos educativos focado nas práticas pedagógicas, com metodologias de pesquisa qualitativa onde a observação participante assume um lugar preponderante na regulação da ação dos pesquisadores.

\section{O projeto Inovação Pedagógica: identidade, teoria e práticas (IPITP) ${ }^{6}$}

\footnotetext{
5 Sobre as discussões sobre currículo ler os trabalhos de Rudd e Goodson (2016), Uljens (2016), Pacheco e Sousa (2016), Morgado (2016), Moreira e Silva Junior (2016), Kovacs e Tinoca (2017), Fino (2016), Sousa (2016), Pedro (2017), Barbosa e Cassiani (2017), Menezes e Dias (2017), Campani e Silva (2019) e Rocha (2020).

${ }^{6} \mathrm{O}$ projeto tem cooperação internacional por meio do protocolo de Cooperação de atividades científicas entre a Universidade da Madeira (Portugal) e a Universidade Federal de Sergipe (UFS). Para esta fase de levantamento de dados, tivemos a colaboração dos estudantes do $2^{\circ}$ Ano do curso de Licenciatura em Ciências da Educação da Universidade da Madeira, na qual destacamos seus nomes: Ana Carolina Leal Nóbrega, Patrícia Sofia Silva Barcelos, Ana Catarina Moura Serrao, Marco Andre Correia Gomes, Ana Isabel Gomes Silva, Catarina Isabel Silva Velosa, Ana Sofia Gonçalves Abreu, Érica Joana Figueira Faria, Ana Sofia Martins de Freitas Joana Olinda Santos Jardim, Ana Patricia Gouveia Salvação, Beatriz Gonçalves Aguiar, Vera Isabel Castro Rocha, Celina Manuela de Sena Aguiar Patrício, Lívia Sisandra da Silva Soares Ferreira, Rosária de Andrade Francisco Silva, Dalila Rodrigues Teixeira, Sara Raquel Rodrigues Silva, Fátima Jacinta Gonçalves da Corte, Neide Maria Santos Gouveia, Joana Catarina Jardim Freitas, Joana Maria Gama Freitas, José Armando Rangel de Abreu, Sara Catarina Carvalho Catanho, Mariana José Silva Fernandes, Maria Matilde Rodrigues Henriques, Nuno Miguel Figueira Lopes, Pedro Miguel Nunes Pimenta.
} 
Preocupados com o volume de informação existente na área de Inovação Pedagógica no acervo digital da Universidade da Madeira, elaborámos o projeto IPITP com os seguintes objetivos: a) Identificar os contributos teóricos, conceptuais e metodológicos na área de Inovação Pedagógica nas pesquisas obtidas no curso de doutoramento em Educação, na especialidade de Inovação Pedagógica, da Faculdade de Ciências Sociais, da Universidade da Madeira; b) Identificar as Boas Práticas reconhecidas contextualmente como inovadoras, para o campo da Pedagogia e da Educação nessas pesquisas; c) Reconhecer a existência de referências identitárias no campo das ciências da educação, na especialidade de Inovação Pedagógica.

No primeiro momento, formulamos as questões do projeto IPITP: a) Que contributos teóricos, conceptuais e metodológicos são identificados nas investigações do curso de doutoramento em Educação, na especialidade de Inovação Pedagógica, da Faculdade de Ciências Sociais, da Universidade da Madeira?; b) Que Boas Práticas são reconhecidas como contextualmente inovadoras, para o campo da Pedagogia e da Educação, relatadas nessas investigações?; c) Que evidências identitárias no campo das Ciências da Educação, na especialidade de Inovação Pedagógica são percetíveis na produção científica do curso de doutoramento em Educação, na especialidade de Inovação Pedagógica?

Tomamos por referência metodológica a metanálise qualitativa segundo Castro (2012) e a Teoria Fundamentada de Strauss (1990), por ser largamente utilizada em pesquisas de abordagem metanalítica qualitativa.

Definimos três eixos para a realização da análise às produções de doutoramento registadas no repositório do DIGI-UMa ${ }^{7}$ : a) Elementos epistemológicos da Inovação Pedagógica, na linha de Inovação Pedagógica, do CIE-UMa; b) Boas Práticas reconhecidas contextualmente como inovadoras, no campo da Pedagogia e da Educação, relatadas nas pesquisas sobre Inovação Pedagógica, do CIE-UMa; c) Elementos de identidade da linha de Inovação Pedagógica, do CIE-UMa. Para a coleta e posterior análise da informação estabelecemos o seguinte protocolo:

${ }^{7}$ DIGIUMa acessível em www.digiuma.pt 
Quadro1 - Protocolo de categorização do corpus de coleta e análise

\begin{tabular}{|c|c|c|c|}
\hline Eixo de análise & $\begin{array}{l}\text { Perguntas } \\
\text { pesquisa }\end{array}$ & Categorias & Entradas na base de dados MQE \\
\hline \multirow{6}{*}{$\begin{array}{l}\text { A } \\
\text { epistemológicos da Inovação } \\
\text { Pedagógica, identificados na } \\
\text { tese }\end{array}$} & \multirow[t]{3}{*}{$\begin{array}{l}\text { Que contributos } \\
\text { teóricos, conceptuais } \\
\text { e metodológicos são } \\
\text { identificados nas } \\
\text { investigações do } \\
\text { curso de } \\
\text { doutoramento em } \\
\text { Educação, na } \\
\text { especialidade de } \\
\text { Inovação } \\
\text { Pedagógica, da } \\
\text { Faculdade de } \\
\text { Ciências Sociais, da } \\
\text { Universidade da } \\
\text { Madeira? }\end{array}$} & $\begin{array}{l}\text { IDENTIFICAÇÃO DA OBRA: } \\
\text { 1. IDENTIFICAÇÃO da obra } \\
\text { 2. AUTOR } \\
\text { 2.ORIENTADOR } \\
\text { 3. ANO de conclusão } \\
\text { 4. TÍ́TULO da obra } \\
\text { 5. NÚMERO de páginas } \\
\text { 6. RESUMO } \\
\text { 7. PALAVRAS-CHAVE } \\
\text { 8. SUMÁRIO }\end{array}$ & $\begin{array}{l}\text { 1. IDENTIFICAÇÃO da obra } \\
\text {-TESE DE DOUTORAMENTO em Ciências da } \\
\text { Educação na especialidade de Inovação Pedagógica } \\
\text { 2. AUTOR } \\
\text { 2. ORIENTADOR } \\
\text { 3. ANO de conclusão } \\
\text { 4. TÍTULO da obra } \\
\text { 5. NÚMERO de páginas } \\
\text { 6. RESUMO } \\
\text { 7. PALAVRAS-CHAVE } \\
\text { 8. SUMÁRIO }\end{array}$ \\
\hline & & $\begin{array}{l}\text { ELEMENTOS TEÓRICOS PARA A } \\
\text { CONCEPTUALIZAÇÃO DE INOVAÇÃO } \\
\text { PEDAGÓGICA: } \\
\text { 9. CAPÍTULO para a conceptualização da } \\
\text { Inovação Pedagógica. } \\
\text { 9.1. CAPÍTULO COMPLETO } \\
\text { 10. DEFINIÇÕES de Inovação Pedagógica } \\
\text { 10.1. AUTORES citados na explanação do } \\
\text { conceito de Inovação Pedagógica }\end{array}$ & $\begin{array}{l}\text { ELEMENTOS TEÓRICOS } \\
\text { CONCEPTUALIZAÇÃO DARA A } \\
\text { PEDAGÓGICA: } \\
\text { INOVAÇÃO } \\
\text { 9. Capítulo para a conceptualização de Inovação } \\
\text { Pedagógica } \\
\text {-A obra contém um CAPÍTULO ESPECÍFICO para a } \\
\text { conceptualização da Inovação Pedagógica. } \\
\text {-A conceptualização de Inovação Pedagógica } \\
\text { EXPLANA-SE ao longo da obra. } \\
\text { 9.1. INCLUIR O CAPÍTULO COMPLETO } \\
\text { 10. DEFINIÇÕES de Inovação Pedagógica } \\
\text { 10.1. AUTORES citados na explanação do conceito de } \\
\text { Inovação Pedagógica }\end{array}$ \\
\hline & & $\begin{array}{l}\text { ELEMENTOS METODOLÓGICOS } \\
\text { UTILIZADOS NA INVESTIGAÇÃO: } \\
\text { 11. METODOLOGIA utilizada } \\
\text { 12. TÉCNICAS E INSTRUMENTOS aplicados } \\
\text { 12.1 PAPEL DO OBSERVADOR (Lapassade, } \\
\text { 2001). }\end{array}$ & $\begin{array}{l}\text { ELEMENTOS METODOLÓGICOS PARA A } \\
\text { INVESTIGAÇÃO } \\
\text { PEDAGÓGICA } \\
\text { 11. METODOLOGIA utilizada } \\
\text {-Qualitativa } \\
\text {-Estudo de Caso (qualitativo) } \\
\text {-Etnográfica } \\
\text { 12. TÉCNICAS E INSTRUMENTOS aplicados } \\
\text {-Questionário } \\
\text {-Entrevista (semiestruturada) } \\
\text {-Entrevista (aberta) } \\
\text {-Entrevista etnográfica } \\
\text {-Análise documental } \\
\text {-Observação participante } \\
\text { 12.1 Se referiu a observação participante refira o } \\
\text { PAPEL DO OBSERVADOR (LAPASSADE, 2001). } \\
\text {-Observação participante periférica } \\
\text {-Observação participante ativa } \\
\text { - Observação participante completa ou total }\end{array}$ \\
\hline & \multirow[t]{2}{*}{$\begin{array}{l}\text { Que Boas Práticas } \\
\text { são reconhecidas } \\
\text { como } \\
\text { contextualmente } \\
\text { inovadoras? }\end{array}$} & $\begin{array}{l}\text { ELEMENTOS EMPÍRICOS PARA A } \\
\text { CONCEPTUALIZAÇÃO DE INOVAÇÃO } \\
\text { PEDAGÓGICA: } \\
\text { 13. QUESTOOES de investigação } \\
\text { 14. PRÁTICAS OBSERVADAS } \\
\text { 15. PRÁTICAS DESENVOLVIDAS }\end{array}$ & 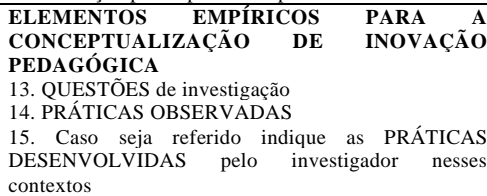 \\
\hline & & $\begin{array}{l}\text { ELEMENTOS SISTEMATIZADOS } \\
\text { SOBRE INOVAÇÃO PEDAGÓGICA: } \\
\text { 16. RESULTADOS } \\
\text { 17. CONCLUSÕES } \\
\text { 18. RECOMENDAÇÕES para outros estudos. }\end{array}$ & $\begin{array}{l}\text { ELEMENTOS SISTEMATIZADOS SOBRE } \\
\text { INOVAÇÃO PEDAGÓGICA } \\
\text { 16. RESULTADOS } \\
\text { 17. CONCLUSÕES } \\
\text { 18. Há RECOMENDAÇÕES para outros estudos? * } \\
\text { 18.1. QUAIS? }\end{array}$ \\
\hline & $\begin{array}{l}\text { Que evidências } \\
\text { identitárias no } \\
\text { campo das ciências } \\
\text { da educação, na } \\
\text { especialidade de } \\
\text { Inovação } \\
\text { Pedagógica são } \\
\text { percetíveis na } \\
\text { produção científica } \\
\text { do curso de } \\
\text { doutoramento em } \\
\text { Educação, na } \\
\text { especialidade de } \\
\text { Inovação } \\
\text { Pedagógica? }\end{array}$ & $\begin{array}{l}\text { ELEMENTOS DE IDENTIDADE DA } \\
\text { LINHA DE PESQUISA EM INOVAÇÃO } \\
\text { PEDAGÓGICA: } \\
\text { CONCEPTUALIZAÇÃO DE INOVAÇÃO } \\
\text { PEDAGÓGICA A PARTIR DO CORPUS } \\
\text { TEÓRICO DAS TESES } \\
\text { CONCEPTUALIZAÇÃO DE INOVAÇÃO } \\
\text { PEDAGÓGICA A PARTIR DO CORPUS } \\
\text { EMPÍRICO DAS TESES }\end{array}$ & 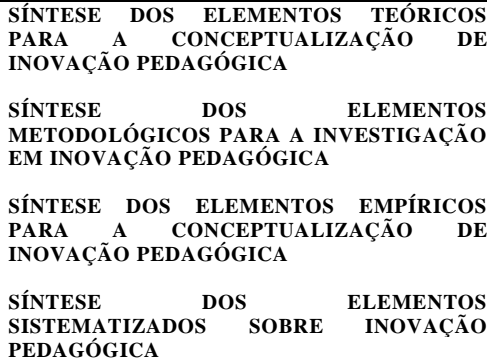 \\
\hline
\end{tabular}

Fonte: Elaboração dos autores (2020)

No segundo momento da pesquisa definimos como critérios de inclusão/exclusão as teses que: a) qualificam o grau de doutoramento em Educação no ramo de Inovação 
Pedagógica na Universidade da Madeira; b) integram o repositório do DIGI-UMa até janeiro de 2020.

No terceiro momento do trabalho partimos para a coleta da informação da pesquisa. Encontramos 21 teses disponíveis, compreendidas entre os anos 2008 e 2019, as quais constituíram o nosso objeto de estudo. Este número de teses foi considerado por nós uma amostra adequada tendo em conta que o universo é constituído por 25 desde a abertura do curso na Universidade da Madeira, até janeiro de 2020 e que o valor disponível (21) representa $84 \%$ do total das teses concluidas.

Procedemos à recolha da informação presente nas 21 teses de doutoramento de acordo com as categorias de análise expostas no Quadro 1.

Efetuamos a introdução das informações no programa informático Metanálise Qualitativa em Educação $(\mathrm{MQE})^{8}$, que elaboramos especificamente para este estudo e que nos permitiu desencadear os seguintes procedimentos: a) Reunir a informação de forma categorizada, em conformidade com a Tabela 1; b) Redefinir novas categorias a partir das informação selecionadas; c) Corporizar uma teoria emergente a partir das etapas anteriores (STRAUSS, 1990).

Figura 1- Apresentação do programa informático MQE

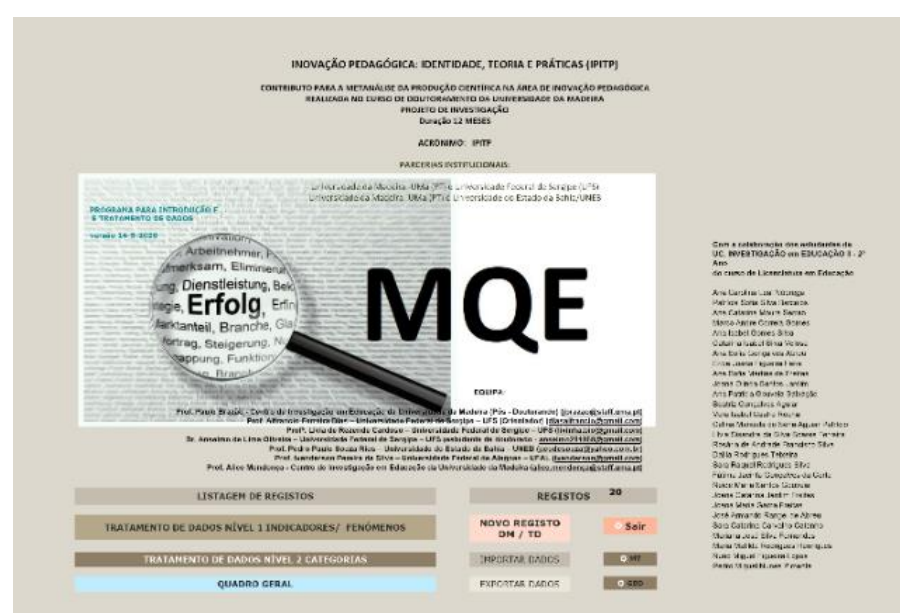

Fonte: Elaboração dos autores (2020)

\footnotetext{
${ }^{8}$ MQE Programa informático elaborado pelos autores para a metanálise qualitativa das teses de doutoramento em Educação, na especialidade de Inovação Pedagógica da Universidade da Madeira, inicialmente publicada em https://a853654.fmphost.com/fmi/webd/MQEv26maio. Este software será também objeto de avaliação no projeto MQE: UMA FERRAMENTA PARA A METANÁLISE QUALITATIVA EM EDUCAÇÃO, desenvolvido no período de 15 de maio de 2020 a 15 de março de 2021, apresentado em https:/www.researchgate.net/project/MQE-UMA-FERRAMENTAPARA-A-METANALISE-QUALITATIVA-EM-EDUCACAO
} 
A efetivação dos procedimentos anteriores viabiliza a descrição interpretativa e a análise da informação apurada, permitindo compreender os fenómenos emergentes (STRAUSS, 1990) bem como construir novas categorias resultantes de uma visão mais abrangente da área analisada.

\section{Resultados}

Considerando que ao realizarmos o presente artigo este projeto se encontra no $3^{\circ}$ momento de desenvolvimento, dispomos de um primeiro grupo de resultados relativos à caracterização da produção científica na área de Inovação Pedagógica do curso de doutoramento em Educação da Universidade da Madeira, que passamos a apresentar.

O gráfico 1 faculta-nos a caracterização dos 21 pesquisadores que concluiram este curso de doutoramento e a cujos dados acedemos, permitindo-nos identificar a respetiva nacionalidade e sexo.

\section{Gráfico 1 - Nacionalidade e sexo dos pesquisadores}

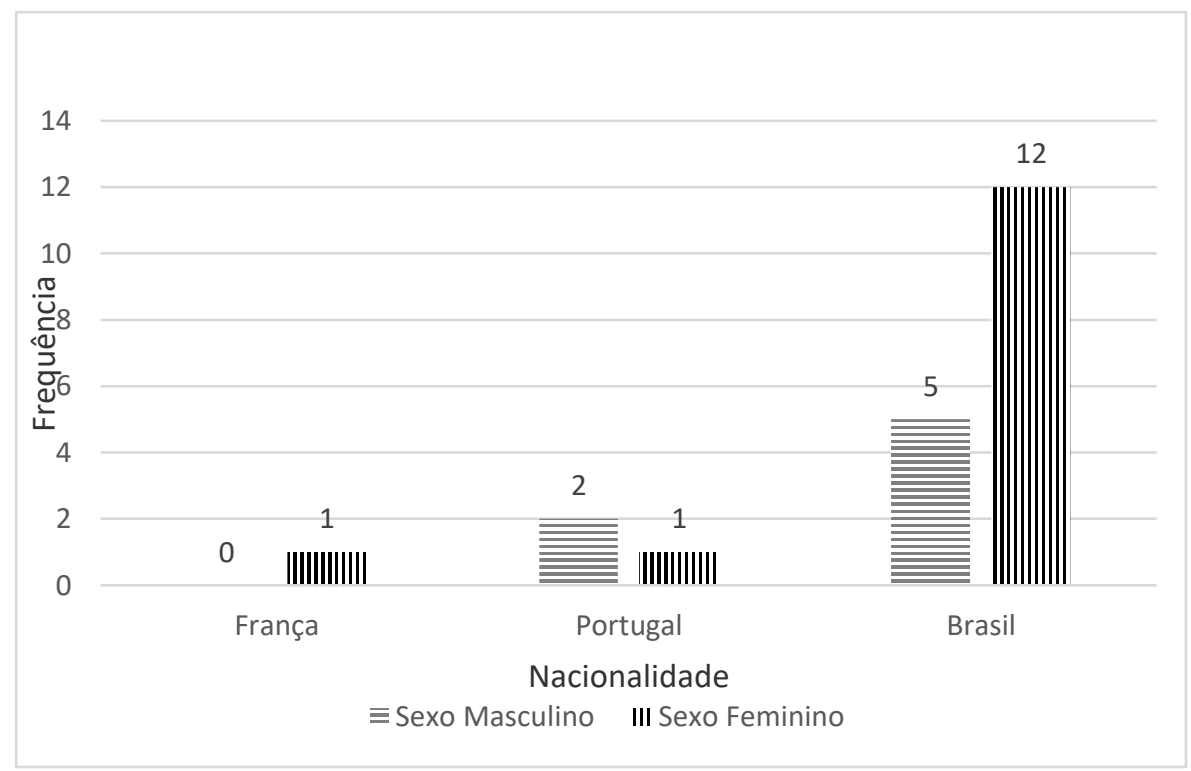

Fonte: DIGI-UMa, 2020 (Elaboração dos autores)

Verificamos que os pesquisadores são preponderantemente femininos $(66,7 \%)$ e possuem maioritariamente nacionalidade brasileira $(81 \%)$. Isto resulta do esforço de internacionalização desta linha de pesquisa desde a abertura do curso de doutoramento, em 2006, através de parcerias com instituições de ensino superior no Brasil que envolveram 
deslocações ao Brasil de professores portugueses para lecionação, e de estudantes estrangeiros à Universidade da Madeira para conclusão dos seus processos avaliativos no curso de doutoramento.

Gráfico 2 - Teses de Doutoramento concluídas em Inovação Pedagógica (2008-2019)

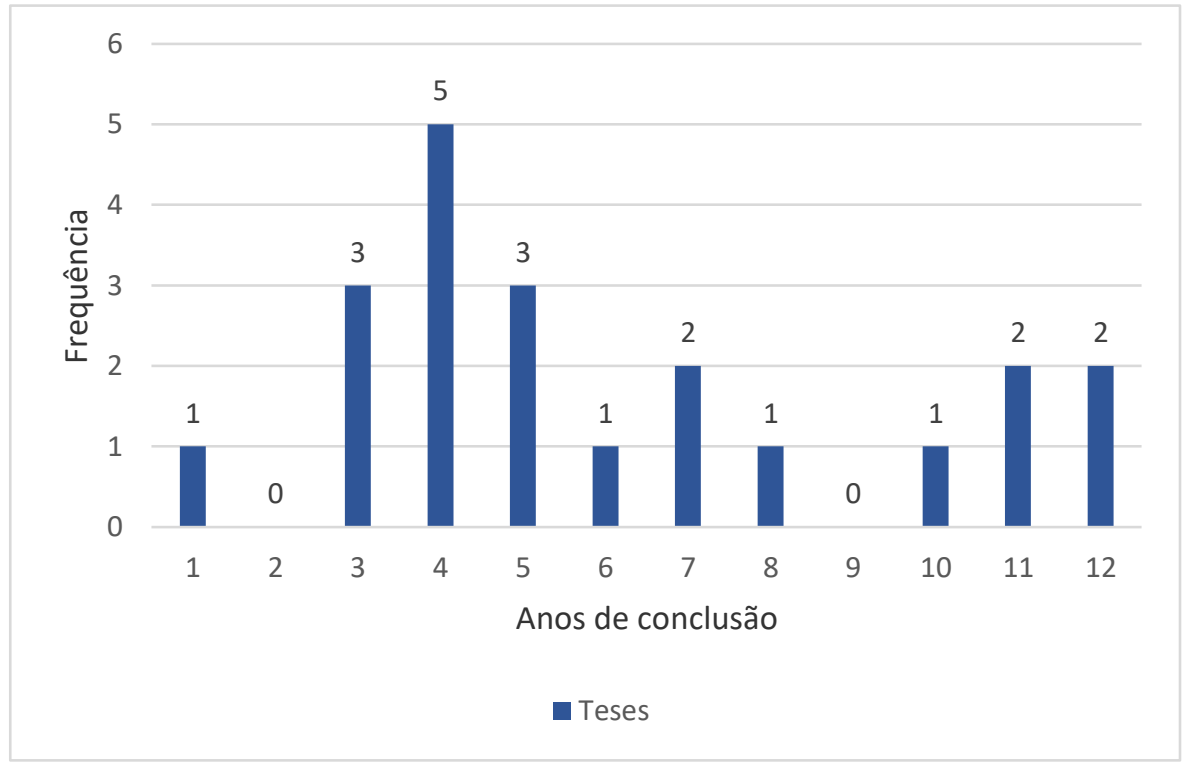

Fonte: DIGI-UMa, 2020 (Elaboração dos autores)

O gráfico 2, permite inferir que entre os anos de 2010 e 2012, foram concluidas mais de metade das totalidades das teses $(52,4 \%)$, o que atesta da concentração desta investigação, concluida com sucesso, naqueles três anos. Os anos subsequentes, assim como os anos anteriores reportam frequencias que oscilam entre 0 e 2.

O número de páginas varia de acordo com cada tese e, os seus valores oscilam entre o máximo de 487 páginas e o mínimo de 278. Este facto decorre do regulamento específico

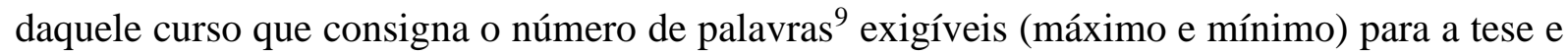
não contempla a indicação do número de páginas. Deste modo, tendo em conta o apuramento do numero de páginas de cada uma das 21 teses, o cálculo da média aritmética reportou 355.

${ }^{9}$ Conforme o Regulamento Específico do curso de doutoramento em Inovação Pedagógica da Universidade da Madeira, no ponto 1 do Artigo $11^{\circ}$ "A tese é escrita com uma extensão não inferior a cem mil nem superior a cento e vinte mil palavras, excluindo resumo, sumário, índices, anexos e bibliografia." 
Gráfico 3 - Orientadores das teses de doutoramento em Inovação Pedagógica

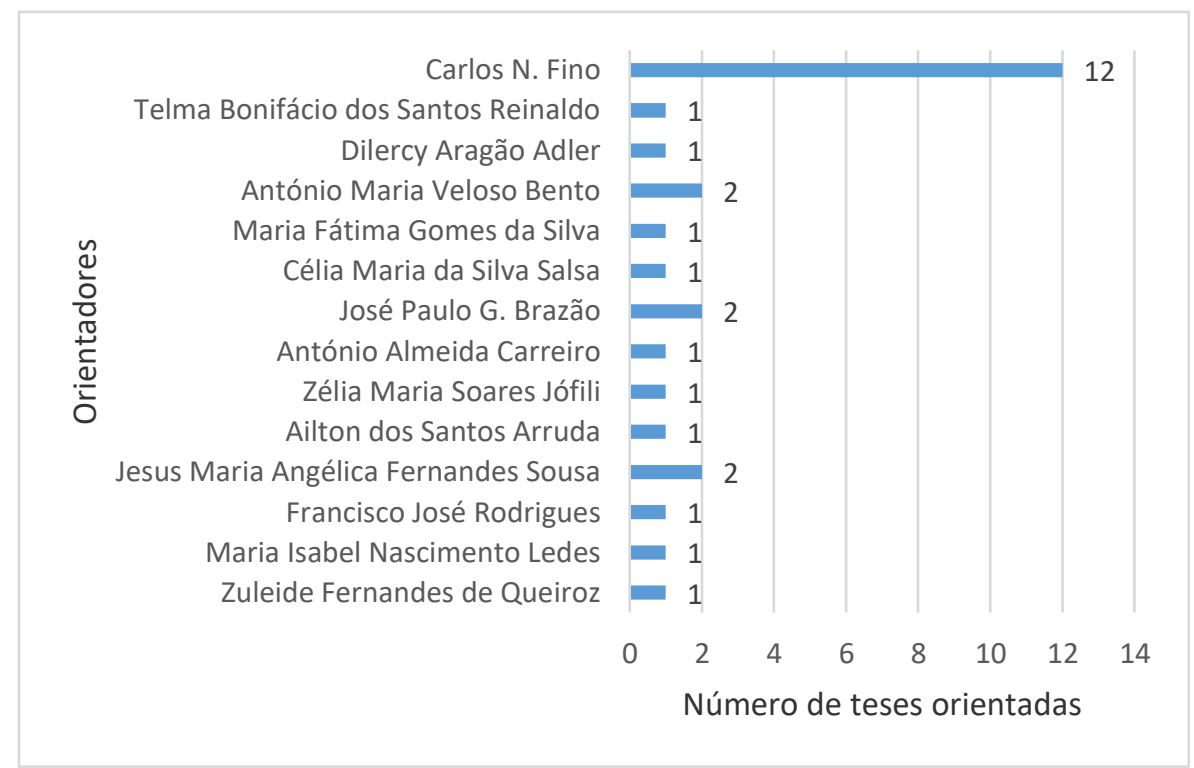

Fonte: DIGI-UMa, 2020 (Elaboração dos autores)

Relativamente à participação dos orientadores nas teses de doutoramento em Inovação Pedagógica (cf. Gráfico 3), observamos que o Professor Carlos Fino (Diretor do curso e pesquisador responsável pela linha de investigação em Inovação Pedagógica) é o orientador com maior participação neste processo (12 orientações). Os Professores Paulo Brazão, António Maria Veloso Bento e Jesus Maria Angélica Fernandes Sousa, orientaram cada um, duas teses. Os restantes professores participaram orientando uma tese. Os aspetos identitários destes trabalhos de pesquisa são maioritariamente marcados pela influência do orientador que mais teses orientou, o Professor Carlos Nogueira Fino, o fundador, diretor e o coordenador da linha de investigação. 
Quadro 2: Temas e contextos de práticas estudadas

\begin{tabular}{|c|c|c|}
\hline Título & $\begin{array}{l}\text { Temas pesquisados em } \\
\text { Inovação Pedagógica }\end{array}$ & $\begin{array}{l}\text { Contextos de Práticas } \\
\text { Pedagógicas estudadas }\end{array}$ \\
\hline $\begin{array}{l}\text { Weblogs, Aprendizagem e } \\
\text { Cultura da Escola: Um estudo } \\
\text { etnográfico numa sala do } 1^{\circ} \text { ciclo } \\
\text { do Ensino Básico }\end{array}$ & $\begin{array}{l}\text { Weblogs } \\
\text { Aprendizagem } \\
\text { Cultura da Escola }\end{array}$ & $\begin{array}{l}\text { Práticas pedagógicas em } \\
\text { TIC na classe do } 4^{\circ} \text { ano } \\
\text { ciclo do Ensino Básico }\end{array}$ \\
\hline $\begin{array}{l}\text { Inovação Pedagógica no Curso de } \\
\text { Pedagogia da Universidade de } \\
\text { Brasília (UnB): um estudo de } \\
\text { abordagem etnográfica }\end{array}$ & Curso de Pedagogia & $\begin{array}{l}\text { Práticas pedagógicas do } \\
\text { curso de Pedagogia da } \\
\text { Universidade de Brasília } \\
\text { (UnB) }\end{array}$ \\
\hline $\begin{array}{l}\text { A escola como espaço privilegiado } \\
\text { para a construção da identidade } \\
\text { negra e afrodescendente: um } \\
\text { estudo de caso da Unidade } \\
\text { Integrada de Ensino } \\
\text { Fundamental Padre António } \\
\text { Vieira }\end{array}$ & $\begin{array}{l}\text { Construção da identidade } \\
\text { negra e afrodescendente }\end{array}$ & $\begin{array}{l}\text { Trabalho curricular sobre } \\
\text { a cultura negra afro- } \\
\text { descendente numa classe } \\
\text { do } 8^{\mathrm{a}} \text { série do IV ciclo do } \\
\text { Ensino Fundamental }\end{array}$ \\
\hline $\begin{array}{l}\text { Educação Inclusiva, utopia } \\
\text { possível: um estudo de caso sobre } \\
\text { o papel da escola na inclusão dos } \\
\text { deficientes mentais na Unidade de } \\
\text { Ensino Básico - UEB Tancredo } \\
\text { Neves - São Luís/MA/Brasil }\end{array}$ & $\begin{array}{l}\text { Educação Inclusiva das } \\
\text { pessoas com deficiência } \\
\text { mental. }\end{array}$ & $\begin{array}{l}\text { O processo de inclusão } \\
\text { de alunos com } \\
\text { deficiência mental na } \\
\text { UEB-Tancredo Neves da } \\
\text { Rede Municipal de } \\
\text { Ensino, assim como a } \\
\text { trajetória educacional de } \\
\text { um aluno com DM } \\
\end{array}$ \\
\hline $\begin{array}{l}\text { A Tarefa Escolar e Suas } \\
\text { Implicações nas Salas de Aula de } \\
\text { EJA: Um Estudo de Caso } \\
\text { Etnográfico }\end{array}$ & $\begin{array}{l}\text { Tarefa Escolar e Suas } \\
\text { Implicações nas Salas de } \\
\text { Aula }\end{array}$ & $\begin{array}{l}\text { Práticas pedagógicas na } \\
\text { aula de Educação de } \\
\text { Jovens e Adultos }\end{array}$ \\
\hline $\begin{array}{l}\text { Ciclos de Aprendizagem: } \\
\text { Caminhos para uma Inovação } \\
\text { Pedagógica das Práticas } \\
\text { Educativas na Cidade do Recife - } \\
\text { Pernambuco? }\end{array}$ & Ciclos de Aprendizagem & $\begin{array}{l}\text { Práticas pedagógicas nas } \\
\text { turmas de primeiro e } \\
\text { segundo ciclos do } \\
\text { Municipio do Recife }\end{array}$ \\
\hline Internet - sala de estudo virtual & $\begin{array}{l}\text { Internet como sala de } \\
\text { estudo virtual }\end{array}$ & $\begin{array}{l}\text { Práticas pedagógicas } \\
\text { numa sala de estudo do } \\
\text { Ensino Superior }\end{array}$ \\
\hline $\begin{array}{l}\text { Ensino Médio e Cultural Juvenil: } \\
\text { um olhar etnográfico sobre a } \\
\text { aula, como espaço de construção } \\
\text { do conhecimento de alunos e } \\
\text { alunas }\end{array}$ & $\begin{array}{l}\text { Ensino Médio e Cultural } \\
\text { Juvenil } \\
\text { construção do } \\
\text { conhecimento de alunos } \\
\text { e alunas }\end{array}$ & $\begin{array}{l}\text { Práticas pedagógicas do } \\
\text { Ensino Médio na cidade } \\
\text { do Recife. }\end{array}$ \\
\hline $\begin{array}{l}\text { O uso das tecnologias no âmbito } \\
\text { da Educação Visual: uma } \\
\text { perspetiva inovadora do } \\
\text { desenvolvimento da capacidade } \\
\text { criadora? }\end{array}$ & $\begin{array}{l}\text { Uso das tecnologias no } \\
\text { âmbito da Educação } \\
\text { Visual }\end{array}$ & $\begin{array}{l}\text { Práticas pedagógicas de } \\
\text { TIC no âmbito da } \\
\text { Educação Visual numa } \\
\text { turma de } 9 \text { ano do Ensino } \\
\text { Básico } \\
\end{array}$ \\
\hline $\begin{array}{l}\text { O Percurso Curricular } \\
\text { Alternativo, um desafio à } \\
\text { Inovação Pedagógica? }\end{array}$ & $\begin{array}{l}\text { Percurso Curricular } \\
\text { Alternativo }\end{array}$ & $\begin{array}{l}\text { Práticas pedagógicas } \\
\text { numa turma de } 5^{\circ} \text { Ano de } \\
\text { Escolaridade com } \\
\text { proposta de Percurso } \\
\text { Curricular Alternativo }\end{array}$ \\
\hline
\end{tabular}




\begin{tabular}{|c|c|c|}
\hline $\begin{array}{l}\text { Uma abordagem etnográfica aos } \\
\text { cenários de aprendizagem de uma } \\
\text { turma de } 5^{\circ} \text { ano com proposta de } \\
\text { PCA }\end{array}$ & & \\
\hline $\begin{array}{l}\text { O Que a Universidade Faz Com a } \\
\text { Cultura Popular O caso da } \\
\text { Capoeira como inovação } \\
\text { pedagógica }\end{array}$ & $\begin{array}{l}\text { Cultura Popular } \\
\text { Capoeira }\end{array}$ & $\begin{array}{l}\text { Práticas pedagógicas da } \\
\text { roda da Capoeira no } \\
\text { Ensino Superior }\end{array}$ \\
\hline $\begin{array}{l}\text { O círculo de cultura na classe } \\
\text { multisseriada: uma inovação } \\
\text { pedagógica? }\end{array}$ & $\begin{array}{l}\text { Cultura na classe } \\
\text { multisseriada }\end{array}$ & $\begin{array}{l}\text { Práticas pedagógicas } \\
\text { numa classe } \\
\text { multisseriada de uma } \\
\text { escola municipal da } \\
\text { cidade de Itapissuma }\end{array}$ \\
\hline $\begin{array}{l}\text { O Processo de Produção da Obra } \\
\text { "Química e Sociedade" como } \\
\text { Inovação Pedagógica para o } \\
\text { Ensino de Química }\end{array}$ & $\begin{array}{l}\text { Produção da Obra } \\
\text { "Química e Sociedade" }\end{array}$ & $\begin{array}{l}\text { Práticas pedagógicas } \\
\text { sobre a produção da Obra } \\
\text { "Química e Sociedade" }\end{array}$ \\
\hline $\begin{array}{l}\text { Literacia Científica e Trabalho } \\
\text { Prático - Um estudo para a } \\
\text { inovação pedagógica em contexto } \\
\text { escolar }\end{array}$ & $\begin{array}{l}\text { Literacia Científica } \\
\text { Trabalho Prático }\end{array}$ & $\begin{array}{l}\text { Práticas Pedagógicas nas } \\
\text { Ciências da Natureza }\end{array}$ \\
\hline $\begin{array}{l}\text { A possibilidade de uma prática } \\
\text { inovadora num trabalho } \\
\text { interdisciplinar do Colégio } \\
\text { Militar de Fortaleza }\end{array}$ & Trabalho interdisciplinar & $\begin{array}{l}\text { Trabalho interdisciplinar } \\
\text { do Colégio Militar de } \\
\text { Fortaleza }\end{array}$ \\
\hline $\begin{array}{l}\text { Práticas educativas interculturais } \\
\text { como Inovação Pedagógica na } \\
\text { Escola Indígena Pedro Ferreira } \\
\text { de Queiroz, Ibimirim- } \\
\text { Pernambuco/Brasil }\end{array}$ & $\begin{array}{l}\text { Práticas educativas } \\
\text { interculturais }\end{array}$ & $\begin{array}{l}\text { Práticas pedagógicas na } \\
\text { Escola Indígena Pedro } \\
\text { Ferreira de Queiroz, } \\
\text { Ibimirim- } \\
\text { Pernambuco/Brasil }\end{array}$ \\
\hline $\begin{array}{l}\text { Inovação pedagógica numa escola } \\
\text { pública: as práticas pedagógicas } \\
\text { inovadoras mediadas pelas } \\
\text { atividades da oficina Rádio Escola }\end{array}$ & $\begin{array}{l}\text { Atividades da oficina } \\
\text { Rádio Escola }\end{array}$ & $\begin{array}{l}\text { Práticas pedagógicas } \\
\text { numa Oficina Rádio } \\
\text { Escola }\end{array}$ \\
\hline $\begin{array}{l}\text { Educação em Astronomia e } \\
\text { Inovação Pedagógica: Desafios e } \\
\text { Possibilidades }\end{array}$ & Astronomia & $\begin{array}{l}\text { Práticas pedagógicas } \\
\text { desenvolvidas pelos } \\
\text { participantes do Clube de } \\
\text { Astronomia Vega }\end{array}$ \\
\hline $\begin{array}{l}\text { Inovação nas práticas de leitura: } \\
\text { Uma realidade ainda distante do } \\
\text { ambiente escolar }\end{array}$ & Práticas de leitura & $\begin{array}{l}\text { Práticas pedagógicas do } \\
\text { "Projeto Baú de Leitura" }\end{array}$ \\
\hline $\begin{array}{l}\text { Reisado Cordão do Caroá: Uma } \\
\text { prática pedagógica inovadora na } \\
\text { cultura popular? }\end{array}$ & $\begin{array}{l}\text { Reisado Cordão do } \\
\text { Caroá } \\
\text { Cultura popular }\end{array}$ & $\begin{array}{l}\text { Prática pedagógica do } \\
\text { Reisado Cordão do Caroá }\end{array}$ \\
\hline $\begin{array}{l}\text { A Prática da Etnomatemática na } \\
\text { Educação do Campo numa } \\
\text { perspetiva de Inovação } \\
\text { Pedagógica na Escola Coronel } \\
\text { Luiz Ignácio Pessoa de Melo, } \\
\text { Aliança-PE-Brasil }\end{array}$ & Educação do Campo & $\begin{array}{l}\text { A Prática da } \\
\text { Etnomatemática na } \\
\text { Educação do Campo na } \\
\text { Escola Coronel Luiz } \\
\text { Ignácio Pessoa de Melo }\end{array}$ \\
\hline
\end{tabular}


Fonte: DIGI-UMa, 2020 (Elaboração dos autores)

Da análise das temáticas especificadas nos Quadros 1 e 2 podemos constatar que há uma grande diversidade de temas estudados no confronto com a inovação pedagógica. Contudo os contextos selecionados para as pesquisas centram-se maioritariamente nos ambientes formais de aprendizagem, tal como atesta o Quadro 3.

Quadro 3: Locais estudados

\begin{tabular}{|c|l|r|r|}
\hline \multicolumn{2}{|c|}{ Locais } & n & \% \\
\hline \multirow{2}{*}{ Ambientes Não Formais de Aprendizagem } & $\begin{array}{l}\text { Espaços Educativos na } \\
\text { Comunidade }\end{array}$ & 3 & 14 \\
\hline \multirow{2}{*}{ Ambientes Formais de Aprendizagem } & Escola & 4 & 19 \\
\cline { 2 - 4 } & Sala de aula & 14 & 67 \\
\hline \multicolumn{2}{|l|}{ Total } & $\mathbf{2 1}$ & $\mathbf{1 0 0}$ \\
\hline
\end{tabular}

Fonte: Elaboração dos autores (2020)

Ou seja, os ambientes formais de aprendizagem foram alvo de $86 \%$ do total das pesquisas e destas, 67\% decorreram em contexto de sala de aula. Apenas 3 investigações (14\%) decorreram em ambientes não formais de aprendizagem o que atesta da importância que os pesquisadores atribuem aos ambientes formais de aprendizagem. A Figura 2 sintetiza esta ilação e atesta da hierarquia concedida aos diferentes contextos de aprendizagem enquanto espaços privilegiados de investigação.

Figura 2 - Hierarquia dos contextos de investigação

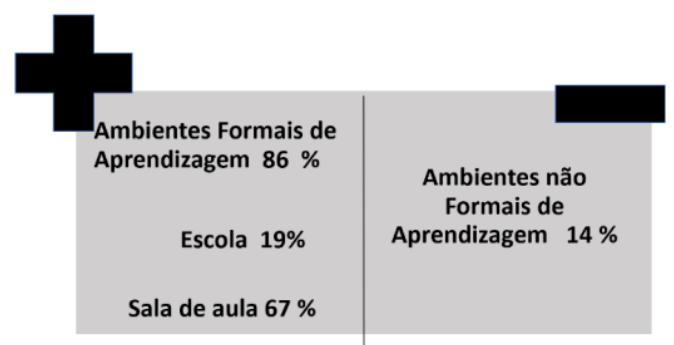

Fonte: Elaboração dos autores (2020)

Estas opções contextuais resultam do grande interesse dos pesquisadores em trabalhar temas com maior relação com os ambientes formais de aprendizagem pois esse campo representa historicamente uma zona de conflito, designadamente ao nível dos invariantes culturais (FINO, 2009) que dificultam a inovação pedagógica. 
Quadro 4: Palavras-chave utilizadas nas teses

\begin{tabular}{|l|l|l|l|r|r|}
\hline Palavras-chave & $\mathbf{n}$ & $\boldsymbol{\%}$ & Palavras-chave & n & \% \\
\hline Aprendizagem & 8 & 12 & Etnomatemática & 1 & 1 \\
\hline Cultura & 9 & 13 & Identidade étnica & 1 & 1 \\
\hline Educação & 10 & 15 & Identidade Negra Afrodescendente & 1 & 1 \\
\hline Etnografia & 13 & 20 & Inovação Pedagógica Dialógica & 1 & 1 \\
\hline Inovação & 2 & 3 & Internet & 1 & 1 \\
\hline Inovação Pedagógica & 18 & 27 & Invisibilidade & 1 & 1 \\
\hline Práticas Pedagógicas & 2 & 3 & LDB Lei de Diretrizes e Bases da & & 1 \\
\hline Tecnologia & 2 & 3 & Linguagens Midiáticas & 1 & \\
\hline "Baú de Leitura" & 1 & 1 & Literacia Científica & 1 & 1 \\
\hline Aprendizagem Colaborativa & 1 & 1 & Livro didático & 1 & 1 \\
\hline Astronomia & 1 & 1 & MEC Ministério da Educação e Cultura & 1 & 1 \\
\hline Aula & 1 & 1 & Mestres da Capoeira & 1 & 1 \\
\hline Capoeira & 1 & 1 & Modelos de Educação & 1 & 1 \\
\hline Círculo de Cultura & 1 & 1 & Observação Participante & 1 & 1 \\
\hline Classe Multisseriada & 1 & 1 & PCR Prefeitura Municipal do Recife & 1 & 1 \\
\hline Construtivismo & 1 & 1 & Pedagogia da Possibilidade & 1 & 1 \\
\hline Contextos de aprendizagens & 1 & 1 & Percurso Curricular Alternativo & 1 & 1 \\
\hline Cultura Escolar & 1 & 1 & Pesquisa-ação & 1 & 1 \\
\hline Cultura Juvenil & 1 & 1 & Práticas educativas interculturais & 1 & 1 \\
\hline Cultura Química & 1 & 1 & Práticas socioculturais & 1 & 1 \\
\hline Cultura Virtual & 1 & 1 & Preconceito Racial & 1 & 1 \\
\hline Currículo & 1 & 1 & Protagonismo & 1 & 1 \\
\hline Deficientes mentais & 1 & 1 & Rádio Escola & 1 & 1 \\
\hline Educação de Jovens e Adultos & 1 & 1 & Reisado & 1 & 1 \\
\hline Educação do Campo & 1 & 1 & Sustentabilidade humanística & 1 \\
\hline Educação inclusiva & 1 & 1 & Tarefa Escolar & 1 \\
\hline Educação Matemática & 1 & 1 & Trabalho Prático & 1 \\
\hline Ensino Médio & 1 & 1 & Utopia Realizável & 1 & 1 \\
\hline Escola indígena & 1 & 1 & Weblogs & 1 \\
\hline Escrita Colaborativa & 1 & 1 & & \\
\hline
\end{tabular}

Fonte: Elaboração dos autores (2020)

A variedade dos temas selecionados para investigação espelhou-se na existência de uma quantidade substancial e diferencial de palavras-chave, cujo detalhe e frequencia constam do Quadro 4.

Daqui decorreu a elaboração da sintese hierárquica (Cf. Figura 3), onde constam todas as palavras-chave incluidas nas teses e cuja frequencia é superior a 1.

Figura 3 - Hierarquia das Palavras-chave 


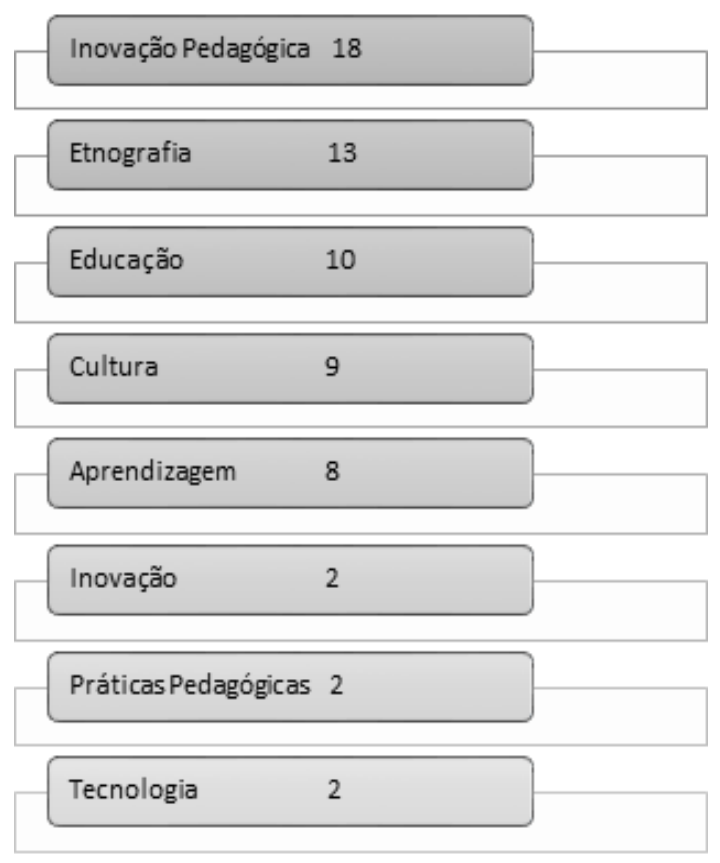

Fonte: Elaboração dos autores (2020)

A palavra-chave Inovação Pedagógica concentra a frequência máxima (27\%). Seguem-se a Etnografia (20\%), a Educação (15\%), a Cultura (13\%), a Aprendizagem (12\%), a Inovação (3\%), as Práticas Pedagógicas (3\%) e a Tecnologia (3\%).

Estes resultados traduzem a importância que os pesquisadores conferem à epistemologia da Inovação Pedagógica o que revela a existencia de uma identidade dos trabalhos efetuados para com a linha de investigação pesquisada.

Quadro 5 - Operacionalização dos objetivos nos resumos das pesquisas

\begin{tabular}{|l|l|}
\hline \multicolumn{1}{|c|}{ Título } & \multicolumn{1}{|c|}{ Objetivos } \\
\hline $\begin{array}{l}\text { Weblogs, Aprendizagem e Cultura da Escola: } \\
\text { Um estudo etnográfico numa sala do 1o ciclo do } \\
\text { Ensino Básico }\end{array}$ & Descrever e interpretar a cultura emergente \\
\hline $\begin{array}{l}\text { Inovação Pedagógica no Curso de Pedagogia } \\
\text { da Universidade de Brasília (UnB): um estudo } \\
\text { de abordagem etnográfica }\end{array}$ & Compreender a natureza da inovação pedagógica \\
\hline $\begin{array}{l}\text { A escola como espaço privilegiado para a a } \\
\text { construção da identidade negra e } \\
\text { afrodescendente: um estudo de caso da } \\
\text { Unidade Integrada de Ensino Fundamental } \\
\text { Padre António Vieira }\end{array}$ & $\begin{array}{l}\text { Descrever e analisar criticamente a cultura } \\
\text { emergente }\end{array}$ \\
\hline $\begin{array}{l}\text { Educação Inclusiva, utopia possível: um estudo } \\
\text { de caso sobre o papel da escola na inclusão } \\
\text { dos deficientes mentais na Unidade de Ensino } \\
\text { Básico - UEB Tancredo Neves - São } \\
\text { Luís/MA/Brasil }\end{array}$ & $\begin{array}{l}\text { Destacar o papel da escola no processo de inclusão } \\
\text { de alunos com deficiência mental }\end{array}$ \\
\hline $\begin{array}{l}\text { A Tarefa Escolar e Suas Implicações nas Salas } \\
\text { de Aula de EJA: Um Estudo de Caso } \\
\text { Etnográfico }\end{array}$ & $\begin{array}{l}\text { Referir o processo de aprendizagem dos alunos da } \\
\text { Educação de Jovens e Adultos }\end{array}$ \\
\hline $\begin{array}{l}\text { Ciclos de Aprendizagem: Caminhos para uma } \\
\text { Inovação Pedagógica das Práticas Educativas }\end{array}$ & $\begin{array}{l}\text { Abordar a temática das possibilidades de inovação } \\
\text { pedagógica no âmbito dos ciclos de aprendizagem }\end{array}$ \\
\hline
\end{tabular}




\begin{tabular}{|c|c|}
\hline ? & \\
\hline Internet - sala de estudo virtual & $\begin{array}{l}\text { Observar o uso que os estudantes dão aos } \\
\text { computadores e, particularmente, à Internet }\end{array}$ \\
\hline $\begin{array}{l}\text { Ensino Médio e Cultural Juvenil: um olhar } \\
\text { etnográfico sobre a aula, como espaço de } \\
\text { construção do conhecimento de alunos e } \\
\text { alunas }\end{array}$ & $\begin{array}{l}\text { Descrever, analisar e interpretar o significado da aula } \\
\text { como espaço de produção do conhecimento e } \\
\text { formação cultural dos jovens. }\end{array}$ \\
\hline $\begin{array}{l}\text { O uso das tecnologias no âmbito da Educação } \\
\text { Visual: uma perspetiva inovadora do } \\
\text { desenvolvimento da capacidade criadora? }\end{array}$ & $\begin{array}{l}\text { Desvelar em que medida o uso das tecnologias na } \\
\text { lecionação da Educação Visual origina práticas } \\
\text { inovadoras, passíveis }\end{array}$ \\
\hline $\begin{array}{l}\text { O Percurso Curricular Alternativo, um desafio à } \\
\text { Inovação Pedagógica? Uma abordagem } \\
\text { etnográfica aos cenários de aprendizagem de } \\
\text { uma turma de } 5 \text { o ano com proposta de PCA }\end{array}$ & $\begin{array}{l}\text { Descrever, compreender e interpretar a cultura } \\
\text { emergente }\end{array}$ \\
\hline $\begin{array}{l}\text { O Que a Universidade Faz Com a Cultura } \\
\text { Popular O caso da Capoeira como inovação } \\
\text { pedagógica }\end{array}$ & $\begin{array}{l}\text { Identificar nos fundamentos afro-brasileiros da } \\
\text { Capoeira, a inovação pedagógica adequada para } \\
\text { subsidiar sua institucionalização }\end{array}$ \\
\hline $\begin{array}{l}\text { O círculo de cultura na classe multisseriada: } \\
\text { uma inovação pedagógica? }\end{array}$ & $\begin{array}{l}\text { Apoiar a introdução de mudanças paradigmáticas que } \\
\text { viessem a se constituir em inovação pedagógica, } \\
\text { numa prática comum }\end{array}$ \\
\hline $\begin{array}{l}\text { O Processo de Produção da Obra "Química e } \\
\text { Sociedade" como Inovação Pedagógica para o } \\
\text { Ensino de Química }\end{array}$ & $\begin{array}{l}\text { Identificar contribuições do uso desse livro na } \\
\text { abordagem de temas socio científicos }\end{array}$ \\
\hline $\begin{array}{l}\text { Literacia Científica e Trabalho Prático - Um } \\
\text { estudo para a inovação pedagógica em } \\
\text { contexto escolar }\end{array}$ & $\begin{array}{l}\text { Discernir as potencialidades do trabalho prático na } \\
\text { criação de práticas pedagógicas heterodoxas onde o } \\
\text { aluno seja socialmente participativo na construção de } \\
\text { conhecimento. }\end{array}$ \\
\hline $\begin{array}{l}\text { A possibilidade de uma prática inovadora num } \\
\text { trabalho interdisciplinar do Colégio Militar de } \\
\text { Fortaleza }\end{array}$ & $\begin{array}{l}\text { Descrever e interpretar, com base nos fundamentos } \\
\text { da etnografia, os fenômenos educativos e as ações } \\
\text { dos sujeitos envolvidos na prática pedagógica }\end{array}$ \\
\hline 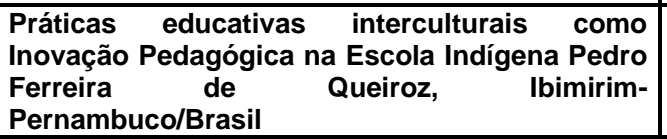 & $\begin{array}{l}\text { Pesquisar sobre as práticas educativas interculturais, } \\
\text { como inovação pedagógica na escola indígena }\end{array}$ \\
\hline $\begin{array}{l}\text { Inovação pedagógica numa escola pública: as } \\
\text { práticas pedagógicas inovadoras mediadas } \\
\text { pelas atividades da oficina Rádio Escola }\end{array}$ & $\begin{array}{l}\text { Verificar se uma situação de construção de } \\
\text { conhecimento é entendida como uma cultura } \\
\text { emergente que se contrapõe a práticas pedagógicas } \\
\text { tradicionais e que pode revelar-se como inovação } \\
\text { pedagógica. }\end{array}$ \\
\hline $\begin{array}{l}\text { Educação em Astronomia e Inovação } \\
\text { Pedagógica: Desafios e Possibilidades }\end{array}$ & $\begin{array}{l}\text { Investigar e analisar as práticas pedagógicas } \\
\text { desenvolvidas pelos participantes do Clube de } \\
\text { Astronomia Vega }\end{array}$ \\
\hline $\begin{array}{l}\text { Inovação nas práticas de leitura: Uma realidade } \\
\text { ainda distante do ambiente escolar }\end{array}$ & $\begin{array}{l}\text { Compreender como se caracterizam e qual a } \\
\text { relevância das práticas pedagógicas do "Projeto Baú } \\
\text { de Leitura", enquanto inovação pedagógica. }\end{array}$ \\
\hline $\begin{array}{l}\text { Reisado Cordão do Caroá: Uma prática } \\
\text { pedagógica inovadora na cultura popular? }\end{array}$ & $\begin{array}{l}\text { Compreender tais técnicas no processo apropriação } \\
\text { do conhecimento lúdico e histórico, na transmissão } \\
\text { para as gerações futuras e na aprendizagem }\end{array}$ \\
\hline $\begin{array}{l}\text { A Prática da Etnomatemática na Educação do } \\
\text { Campo numa perspectiva de Inovação } \\
\text { Pedagógica na Escola Coronel Luiz Ignácio } \\
\text { Pessoa de Melo, Aliança-PE-Brasil }\end{array}$ & $\begin{array}{l}\text { Investigar se existia inovação pedagógica na prática } \\
\text { da Etnomatemática na Educação do Campo }\end{array}$ \\
\hline
\end{tabular}

Fonte: Elaboração dos autores (2020)

O Quadro 5 apresenta a operacionalização dos objetivos nas pesquisas efetuadas e, face a cada tema pesquisado, identificámos os objetivos propostos por cada investigador. A categorização dos objetivos aqui explanados possibilitou-nos sintetizar a informação relativa à taxonomia dos objetivos definidos para as pesquisas bem como a respetiva frequência. $\mathrm{O}$ gráfico 4, apresenta, por ordem de grandeza, os verbos operativos mais frequentes: descrever (5 citações), compreender (4 citações), interpretar (4 citações), investigar (2 citações), 
identificar (2 citações), e os restantes verbos operativos utilizados com menor frequencia (1 citação): analisar, destacar, abordar, observar, desvelar, apoiar, discernir, pesquisar e verificar.

Gráfico 4 - Objetivos das pesquisas

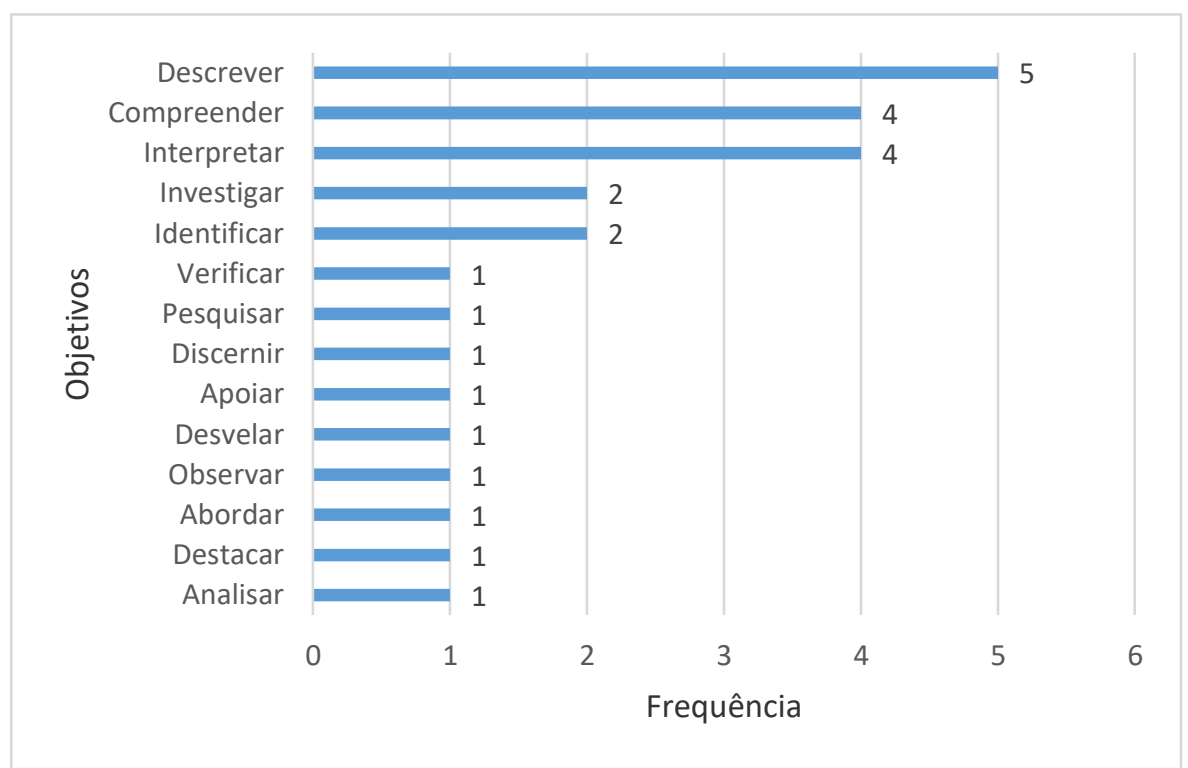

Fonte: Elaboração dos autores (2020)

Não incluímos neste artigo o estudo epistemológico da inovação pedagógica desta linha de investigação. Este eixo de análise será melhor tratado em futuras publicações. Podemos avançar desde já que a perfusão entre a teoria e a prática bem como o facto do método de pesquisa descritiva utilizado, direcionam a construção dos objetivos operatórios como descrever, compreender, e interpretar (cf. Gráfico 4) e é resultado da influência epistemológica da Inovação Pedagógica desta linha de investigação.

Esse aspeto constitui ainda um elemento de identidade nos trabalhos efetuados.

\section{Considerações finais}

A análise da produção científica sistematizada neste trabalho permitiu evidenciar alguns aspetos caracterizadores e fortemente marcantes do ponto de vista identitário da linha de investigação em Inovação Pedagógica da Universidade da Madeira.

Verificámos que os pesquisadores são preponderantemente femininos e de nacionalidade brasileira, resultado da internacionalização desta linha de pesquisa desde 2006 com especial incidência no Brasil. 
Os aspetos identitários destes trabalhos de pesquisa são definitivamente marcados pela influência do orientador que mais teses orientou, o Professor Carlos Nogueira Fino, o fundador, diretor e o coordenador da linha de investigação.

Por outro lado, constatou-se que a grande maioria das pesquisas privilegiou o espaço físico da sala de aula e as questões investigativas visaram predominantemente descrever, compreender e interpretar fenómenos educativos.

Embora o estudo epistemológico da linha de investigação em Inovação Pedagógica constitua um eixo de análise a aprofundar em futuras publicações, podemos para já avançar com a constatação de que a escolha de temas de maior relação com o espaço de educação formal faz aumentar a possibilidade de identificar e evidenciar os invariantes culturais que dificultam a Inovação Pedagógica.

A importância atribuída à epistemologia da Inovação Pedagógica revela por um lado a existência de uma identidade dos trabalhos efetuados nesta linha de investigação, e por outro, mostra a perfusão entre a teoria e a prática, utilização com métodos de pesquisa descritiva utilizado.

\section{AGRADECIMENTOS: CNPq}

\section{REFERENCIAS}

ALMADA, C.; SOUSA, J. M. Revoluções, Paradigmas e Inovação Pedagógica: provocações para um debate contemporâneo. In: ENCONTRO INTERNACIONAL TRABALHO E PERSPETIVA DE FORMAÇÃO DE TRABALHADORES (1713-1724). Fortaleza. Anais [...]. Fortaleza: LABOR/UFC - Núcleo de Pesquisa em Educação Profissional - NUPEP/IFCE, Universidade Federal do Ceará, 2017.

AYRES, D. Educação Inclusiva, utopia possível: um estudo de caso sobre o papel da escola na inclusão dos deficientes mentais na Unidade de Ensino Básico - UEB Tancredo Neves São Luís/MA/Brasil. 2010.Tese (Doutorado) - Universidade da Madeira, 2010.

AZEVEDO, S. Inovação nas práticas de leitura: uma realidade ainda distante do ambiente escolar. 2018. 326 f. Tese (Doutorado em Ciências da Educação) - Universidade da Madeira, 2018.

BELLO, O. A possibilidade de uma prática inovadora num trabalho interdisciplinar do Colégio Militar de Fortaleza. 2014. 388 f. Tese (Doutorado em Ciências da Educação) Universidade da Madeira, 2014.

BICUDO, M. Meta-análise: seu significado para a pesquisa qualitativa. REVEMAT, Florianópolis, v. 9, Ed. Temática, p. 07-20, jun. 2014. 
BOTTECHIA, J. O Processo de Produção da Obra "Química e Sociedade" como Inovação Pedagógica para o Ensino de Química. Tese de doutoramento apresentada na Universidade da Madeira, 2012. 333 f. Tese (Doutorado) - Universidade da Madeira, 2012. Disponível em: http://hdl.handle.net/10400.13/1077. Acesso em: 29 maio 2020.

BRAZÃO, P. Weblogs, aprendizagem e cultura da escola: um estudo etnográfico numa sala do $1^{\circ}$ ciclo do Ensino Básico. 2008. 334 f. Tese (Doutorado) - Universidade da Madeira, 2008. Disponível em: http://hdl.handle.net/10400.13/127. Acesso em: 29 maio 2020.

CABRAL, M. Práticas educativas interculturais como inovação pedagógica na escola indígena Pedro Ferreira de Queiroz, Ibimirim- Pernambuco/Brasil. 2015. 333 f. Tese (Doutorado em Ciências da Educação) - Universidade da Madeira, 2015. Disponível em: http://hdl.handle.net/10400.13/1044. Acesso em: 29 maio 2020.

CARREIRA, S. Literacia Científica e Trabalho Prático - Um estudo para a inovação pedagógica em contexto escolar. 2014. 421 f. Tese (Doutorado em Ciências da Educação) Universidade da Madeira, 2014. Disponível em: http://hdl.handle.net/10400.13/918. Acesso em: 29 maio 2020.

CASTRO, A. A. Revisão sistemática e meta-análise. 2001. Disponível em: http://metodologia.org/wp-content/uploads/2010/08/meta1.PDF. Acesso em 23 de junho de 2012.

CASTRO, A. A.; SACONATO, H.; GUIDUGLI, F; CLARK, O. A. C. Curso de revisão sistemática e metanálise [Online]. São Paulo: LED-DIS/UNIFESP, 2002. Disponível em: http://www.virtual.epm.br/cursos/metanalise. Acesso em: 23 jun. 2012.

CAVALCANTI, R. O círculo de cultura na classe multisseriada: uma inovação pedagógica?. 2012. Tese (Doutorado) - Universidade da Madeira, 2012. Disponível em: http://hdl.handle.net/10400.13/1450. Acesso em: 29 maio 2020.

CAMPANI, A.; SILVA, R. M. G. da; SILVA, M. do S. S. e. Inovação curricular no ensino superior: desafios e possibilidades. Revista on line de Política e Gestão Educacional, v. 23, p. 785-797, out. 2019. Disponível em:

https://periodicos.fclar.unesp.br/rpge/article/view/13015. Acesso em: 29 maio 2020. DOI: https://doi.org/10.22633/rpge.v23iesp.1.13015.

COOPER, H. Research synthesis and meta-analysis: A step-by-step approach. 3. ed. Thousand Oaks, CA: Sage, 2010.

CORREIA, F. Internet - sala de estudo virtual. Tese (Doutorado) - Universidade da Madeira, 2011. Disponível em: http://hdl.handle.net/10400.13/1803. Acesso em: 29 maio 2020.

FIGUEIREDO FILHO, et al. O que é, para que serve e como se faz uma meta-análise? Teoria \& Pesquisa: Revista de Ciência Política, v. 23, n. 2, p. 205-228, 2014. 
DOUNIS, B. A Tarefa Escolar e Suas Implicações nas Salas de Aula de EJA: Um Estudo de Caso Etnográfico. 2011. Tese (Doutorado em Ciências da Educação) - Universidade da Madeira, 2011. Disponível em: http://hdl.handle.net/10400.13/1456. Acesso em: 29 maio 2020.

DUARTE, A. O uso das tecnologias no âmbito da Educação Visual: uma perspetiva inovadora fomentadora do desenvolvimento da capacidade criadora? 2011. Tese (Doutorado em Ciências da Educação) - Universidade da Madeira, 2011. Disponível em: http://hdl.handle.net/10400.13/1457. Acesso em: 29 maio 2020.

FARIAS, A. Reisado Cordão do Caroá: Uma prática pedagógica inovadora na cultura popular? 2019. Tese (Doutorado em Ciências da Educação) - Universidade da Madeira, 2019. Disponível em: http://hdl.handle.net/10400.13/2585. Acesso em: 29 maio 2020

FILHO, C. O que a Universidade faz com a cultura popular: o caso da capoeira como inovação pedagógica. 2012. Tese (Doutorado em Ciências da Educação) - Universidade da Madeira, 2012. Disponível em: http://hdl.handle.net/10400.13/1455. Acesso em: 29 maio 2020

FINO, C. N. Inovação e invariante (cultural). In: RODRIGUES, L.; BRAZÃO, P. (Orgs.). Políticas educativas: discursos e práticas. Funchal: Grafimadeira, p. 192-209, 2009.

FINO, C. Investigação e inovação (em educação). In: FINO, C. N.; SOUSA, J. M. (2011). Pesquisar para mudar (a educação). Funchal: Universidade da Madeira - CIE-Uma, p. 2948, 2011.

FINO, C. Matética e inovação pedagógica: o centro e a periferia. In: GOUVEIA, F.; PEREIRA, M. G. (Orgs.). Didática e Matética. Funchal: Universidade da Madeira - CIEUMa, p. 253-259, 2016.

FINO, C. N. Inovação Pedagógica e Ortodoxia Curricular. Revista Tempos e Espaços em Educação, São Cristóvão, v. 9, n. 18, p. 13-22, 14 abr. 2016. Disponível em: https://seer.ufs.br/index.php/revtee/article/view/4959. Acesso em: 17 abr. 2020.

FINO, C. Dewey, Papert, Construcionismo e Currículo. In: SOUSA, J. M.; FINO, C. N. (Orgs.). (Contra) Tempos de Educação e Democracia, Evocando John Dewey. Funchal: Universidade da Madeira, CIE-UMa, p. 21-30, 2017.

FINO, C. A revolução digital e a sua "pedagogia” hegemónica. In: FRAGA, N. (Org.). O Professor do Século XXI em Perspetiva Comparada: Transformações e Desafios para a Construção de Sociedades Sustentáveis. Funchal: CIE-Uma, p. 57-69, 2019.

FINO, C.; SOUSA, J. M. Avaliação dos cursos em Ciências da Educação de uma Universidade da ultraperiferia: o caso da Universidade da Madeira. In: CONGRESSO SPCE, 13., 2016. Viseu. Anais [...]. Viseu, p. 1741-1750, 2016.

GLASER, B. G.; STRAUSS, A. L. The discovery of grounded theory: Strategies for Qualitative Research. New York: Aldine de Gruyter, 1967.

KUHN, T. S. A estrutura das revoluções científicas. São Paulo: Perspectiva, 2011. 
KOVACS, H.; TINOCA, L. Unfreeze the pedagogies: introduction of a new innovative measure in Portugal. Revista Tempos e Espaços em Educação, São Cristóvão, v. 10, n. 23, p. 73-86, 2017. Disponível em: https://seer.ufs.br/index.php/revtee/article/view/7446. Acesso em: 3 jan. 2020.

LOPES, A. L. M.; FRACOLLI, L. A. Revisão sistemática de literatura e metassíntese qualitativa: considerações sobre sua aplicação na pesquisa em enfermagem. Texto, Contexto, Enfermagem, Florianópolis, p. 771-778, out./dez. 2008.

LOPES, A. W. Inovação pedagógica numa escola pública: as práticas pedagógicas inovadoras mediadas pelas atividades da oficina Rádio Escola. 2017. $311 \mathrm{f}$. Tese (Doutorado em Ciências da Educação) - Universidade da Madeira, 2017.

LOVATTO, P. A. et al. Meta-análise em pesquisas científicas - enfoque em metodologias. Revista Brasileira de Zootecnia, v. 36, p. 285-294, 2007.

MONTEIRO, M. Inovação Pedagógica no Curso de Pedagogia da Universidade de Brasília (UnB): um estudo de abordagem etnográfica. 2010. $373 \mathrm{f}$. Tese (Doutorado) Universidade da Madeira, 2010.

MOREIRA, A. F.; SILVA JÚNIOR, P. M. DA. Currículo, Transgressão e Diálogo: quando outras possibilidades se tornam necessárias. Revista Tempos e Espaços em Educação, São Cristóvão, v. 9, n. 18, p. 45-54, 2016. Disponivel em:

https://seer.ufs.br/index.php/revtee/article/view/4962. Acesso em: 17 abr. de 2020.

MORGADO, J. C. O professor como decisor curricular: de ortodoxo a cosmopolita. Revista Tempos e Espaços em Educação, São Cristóvão, v. 9, n. 18, p. 55-64, 2016. Disponivel em: https://seer.ufs.br/index.php/revtee/article/view/4964. Acesso em: 17 abr. de 2020.

MENEZES, C. A. A; DIAS, A. F. Que inovação pedagógica a pedagogia queer propõe ao currículo escolar?. Revista Tempos e Espaços em Educação, São Cristóvão, v. 10, n. 23, p. 37-48, 2017. Disponível em: https://seer.ufs.br/index.php/revtee/article/view/7443. Acesso em: 3 jan. 2020. DOI: https://doi.org/10.20952/revtee.v10i23.7443

NASCIMENTO, C. Educação em Astronomia e Inovação Pedagógica: Desafios e Possibilidades. 2018. 369 f. Tese (Doutorado em Ciências da Educação) - Universidade da Madeira, 2018. Disponível em: http://hdl.handle.net/10400.13/2699. Acesso em: 3 jan. 2020.

PEREIRA, J. Ensino médio e cultura juvenil: um olhar etnográfico sobre a aula, como espaço de construção do conhecimento de alunos e alunas? 2011. $333 \mathrm{f}$. Tese (Doutorado em Ciências da Educação) - Universidade da Madeira, 2011. Disponível em: http://hdl.handle.net/10400.13/1461. Acesso em: 3 jan. 2020.

PEREIRA, M. O Percurso Curricular Alternativo, um desafio à Inovação Pedagógica? Uma abordagem etnográfica aos cenários de aprendizagem de uma turma de $5^{\circ}$ ano com proposta de PCA. 2012. 422 f. Tese (Doutorado em Ciências da Educação) - Universidade da Madeira, 2012. Disponível em: http://hdl.handle.net/10400.13/580. Acesso em: 3 jan. 2020. 
PACHECO, J. A.; SOUSA, J. O (pós) crítico na Desconstrução Curricular. Revista Tempos e Espaços em Educação, São Cristóvão, v. 9, n. 18, p. 65-74, 2016. Disponível em: https://seer.ufs.br/index.php/revtee/article/view/4971. Acesso em: 17 abr. 2020.

PEDRO, N. Ambientes educativos inovadores: o estudo do fator espaço nas 'salas de aula do futuro’ portuguesas. Revista Tempos e Espaços em Educação, São Cristóvão, v. 10, n. 23, p. 99-108, 2017. Disponível em: https://seer.ufs.br/index.php/revtee/article/view/7448. Acesso em: 17 abr. 2020. DOI: https://doi.org/10.20952/revtee.v10i23.7448

PINTO, CÂNDIDA M. Meta-análise qualitativa como abordagem metodológica para pesquisa em letras. In: ENCONTRO DA ABCP, 9., 2014. Brasília. Anais [...]. Brasília, DF, 2014. Disponível em:

http://proxy.furb.br/ojs/index.php/atosdepesquisa/article/viewFile/4023/2491 Acesso em 20 out 2018.

ROCHA, Rosineide de Andrade; FISCARELLI, Sílvio Henrique; RODRIGUES, Rodolfo Augusto. Caminhos para a inovação no contexto educativo e escolar: o papel da mídiaeducação. Revista on line de Política e Gestão Educacional, [S.1.], p. 270-284, jan. 2020. Disponível em: https://periodicos.fclar.unesp.br/rpge/article/view/13422. Acesso em: 29 maio 2020. DOI: https://doi.org/10.22633/rpge.v24i1.13422

RIBEIRO, M. Ciclos de Aprendizagem: Caminhos para uma Inovação Pedagógica das Práticas Educativas na Cidade do Recife - Pernambuco. 2010. Tese (Doutorado em Ciências da Educação) - Universidade da Madeira, 2010. Disponível em: http://hdl.handle.net/10400.13/1442. Acesso em: 29 maio 2020.

RUDD, T.; GOODSON, I. F. Refraction as a tool for understanding action and educational orthodoxy and transgression. Revista Tempos e Espaços em Educação, São Cristóvão, v. 9, n. 18, p. 99-110, 2016. Disponível em: https://seer.ufs.br/index.php/revtee/article/view/4968. Acesso em: 29 maio 2020. DOI: https://doi.org/10.20952/revtee.v9i18.4968

SANTOS, C. A escola como espaço privilegiado para a construção da identidade negra e afrodescendente: um estudo de caso da Unidade Integrada de Ensino Fundamental Padre Antonio Vieira. 2011. Tese (Doutorado em Ciências da Educação) - Universidade da Madeira, 2010. Disponível em: http://hdl.handle.net/10400.13/1446. Acesso em: 29 maio 2020.

SOUSA, J. M.; FINO, C. N. Um Mestrado em Inovação Pedagógica. I-V. Jornal Tribuna da Madeira, 24 jun. 2005.

SOUSA, J. M.; FINO, C. N. Inovação e incorporação de novos saberes: o desenho curricular de um mestrado em Inovação Pedagógica. In: CONGRESSO DA SPCE, 8., 2007. "Cenários da educação/formação: Novos espaços, culturas e saberes". Castelo Branco. Anais [...]. Castelo Branco: SPCE, 2007.

SOUSA, J. M. Repensar o currículo como emancipador. Revista Tempos e Espaços em Educação, São Cristóvão, v. 9, n. 18, p. 111-120, 2016. Disponível em: https://seer.ufs.br/index.php/revtee/article/view/4969. Acesso em: 17 abr. de 2020. DOI: https://doi.org/10.20952/revtee.v9i18.4969 
SOUZA, M. A prática da etnomatemática na educação do campo numa perspectiva de inovação pedagógica na escola Coronel Luiz Ignácio Pessoa de Melo, Aliança-PE-Brasil. 2019. Tese (Doutorado) - Universidade da Madeira, 2019.

STRAUSS, A. L.; CORBIN, J. Basics of qualitative research: Grounded Theory, Procedures and Techniques. Newbury: SAGE, 1990.

TAROZZI, M. O que é grounded theory? Metodologia de pesquisa e de teoria fundamentada nos dados. Petrópolis, RJ: Vozes, 2011.

ULJENS, M. Non-Affirmative curriculum theory in a cosmopolitan era? Revista Tempos e Espaços em Educação, São Cristóvão, v. 9, n. 18, p. 121-132, 2016. Disponível em: https://seer.ufs.br/index.php/revtee/article/view/4970. Acesso em: 21 maio 2020. DOI: https://doi.org/10.20952/revtee.v9i18.4970

\section{Como referenciar este artigo}

BRAZÃO, Paulo; DIAS, Alfrancio Ferreira; MENDONÇA, Alice; CARDOSO, Lívia de Rezende. Caracterização da produção científica na área de Inovação Pedagógica do curso de doutorado da Universidade da Madeira. Revista on line de Política e Gestão Educacional, Araraquara, v. 24, n. 2, p. 571-592, maio/ago. 2020. e-ISSN:1519-9029. DOI: https://doi.org/10.22633/rpge.v24i2.13742

Submetido em: 20/02/2020

Aprovado em: 15/03/2020

Publicado em: 09/04/2020 